\title{
Prevalence and factors associated with visual inspection of the cervix after acetic acid application positive result among female civil servants and wives of civil servants in Jakarta
}

\author{
Authors: Lady MF Sirait, ${ }^{\mathrm{A}}$ Luh A Anggreni, ${ }^{\mathrm{A}}$ Chitra A Pradibta, ${ }^{\mathrm{A}}$ Widyastuti Widyastuti, ${ }^{\mathrm{A}}$ Wisnu E Prasetyo, ${ }^{\mathrm{A}}$ Hani D
} Puspitasari $^{B}$ and Laila Nuranna ${ }^{B}$

\begin{abstract}
Aims
The purpose of this study was to describe the implementation of visual inspection of the cervix with acetic acid (VIA) among female civil servants and wives of civil servants in Special Capital Region of Jakarta in October 2017.

\section{Methods}

The VIA test was performed in all ministries and government sectors in provinces of Indonesia, in order to raise public awareness towards cervical cancer. Jakarta was one of the cities to perform this VIA test. Early detection through VIA screening test is needed since cervical cancer ranks as the second most frequent cancer among women in Indonesia. A secondary data analysis was conducted based on the data from 43 ministries and government sectors in Jakarta that performed VIA testing in October 2017 using Minitab version 17. The VIA test was used as the screening method and was performed by doctors and midwives with technical supervision by a gynaecologist. The study design is cross-sectional and used to understand the prevalence of various conditions in 8,848 women. Chi-square statistical test was performed to analyse the data.
\end{abstract}

Results

The VIA test was performed in 8,001 women out of 8,848. The VIA test-positive rate was $1.35 \%(108 / 8,001)$, see Table 1 . The risk factors that can significantly influence the result of VIA positive were number of marriages, parity, smoking habits and the use of hormonal contraception.

\section{Conclusion}

The findings of pre-cancerous lesions were not only found in the subject between 30 - and 50 -year-olds group, but also below the 30-year-olds group. To support national cervical cancer prevention campaign, VIA test among female civil servants and wives of civil servants needs to be conducted regularly.

\section{Conflict of interest statement}

None declared.

Table 1. Achievement of the visual inspection of the cervix with acetic acid test

\begin{tabular}{lllllll} 
Patients & Total VIA test & Normal & Gynaecological disorders & VIA negative & VIA positive & Suspicious for malignancy \\
8,848 & 8,001 & 6,776 & 944 & 7,727 & 108 & 21 \\
\hline VIA = visual inspection of the cervix with acetic acid.
\end{tabular}

Authors: ${ }^{\text {ADepartment }}$ of Health of Special Capital Region of Jakarta, Jakarta, Indonesia; ${ }^{B}$ Department of Obstetrics and Gynecology, Faculty of Medicine Universitas Indonesia Cipto Mangunkusumo Hospital, Jakarta, Indonesia 